\title{
Effect of Methylglyoxal on Soluble Receptor For Advanced Glycation End Products (sRAGE) Of Pre-Osteoblast MC3T3E1 Cell Line
}

\author{
Izaak Zoelkarnain Akbar(*), Nur Permatasari(**), Djoko Wahono Soeatmadji(**), Handono Kalim(**), \\ Mohammad Hidayat(***)
}

\section{SUMMARY}

Methylgyoxal (MG) is reactive dicarbonyl compound was found in high level in blood of diabetic patients. Methlyglyoxal was more reactive compared to glucose and have toxic effect through AGEs. Soluble Receptor for Advanced Glycation End Products (sRAGE) act as a scavenger and decoy receptor for AGEs. This study aimed to investigate the effect of changes intracellularly redox status on sRAGE levels in preosteoblast MC3T3E1 exposed to MG. The changes of redox status was obtained by blockade of superoxide dismutase (Diethylthiocarbamoic acid/DETCA), blockade of gluthatione peroxidase (mercapto succinate/MS), and chelating of iron (defferoxamine/DFX). SRAGE levels was evaluated by enzyme linked imunnosorbent assay technique. The levels of sRAGE in MG-exposed group or DETCA-exposed group was significantly increased than that in control group $(\mathrm{P}<0.05)$. The levels of sRAGE in MG+DETCA-exposed group was significantly decrease compared with DETCA-exposed group $(P<0.05)$. The levels of sRAGE was significantly increased in MS-exposed group or MG+MS-exposed group than that in control group, respectively $(P<0.05)$. Concluded that the change of redox status by antioxidant blocker or MG exposure would increases sRAGE levels in preosteoblast MC3T3E1 cell line. The modulation of redox state by antioxidant blocker does not affect SRAGE level in the presence of MG. Iron chelating does not change the sRAGE level.

Key words: preosteoblast MC3T3E1 cell line; methylgyoxal; reactive oxygen species; $S R A G E$

*Department of Orthopaedic and Traumatology, Ulin General Hospital, Faculty of Medicine, University of Lambung Mangkurat, Banjarmasin, South Kalimantan, Indonesia

**Department of Pharmacology, Faculty of Medicine, University of Brawijaya, Malang, East Java, Indonesia

***Department of Internal Medicine, Saiful Anwar General Hospital, Faculty of Medicine, University of Brawijaya, Malang, East Java, Indonesia

****Department of Orthopaedic and Traumatology, Saiful Anwar General Hospital, Faculty of Medicine, University of Brawijaya, Malang, East Java, Indonesia

Ayrı basım isteği: Izaak Zoelkarnain Akbar., MD., PhD

Department of Orthopaedic, Ulin General Hospital,

Faculty of Medicine, University of Lambung Mangkurat, Banjarmasin,

South Kalimantan, Indonesia.

Address: Jl. A. Yani Km 2 No.43, Banjarmasin, South Kalimantan, Indonesia Phone: +628125050005 Fax: +625113252555

E-mail: izaakakbar@yahoo.co.id

Date submitted: May 11, 2013• Data accepted: Aug 12, 2013• Online publication date: June 20.2014

\section{Introduction}

Methylglyoxal is formed non-enzymatically by dephosphorylation of triose phosphates and is efficently catabolise to D-lactate by the glyoxalase pathway. Plasma concentrations of methylgyoxal is increase in diabetic patients [1]. Methylglyoxal is biologically active and would irreversible bind into protein amino acid, protein and nucleic acid, resulting in Methylglyoxal-derived Advanced Glycation End Products (MAGEs), as a structure that bind to AGEs receptors (RAGE) [2]. RAGE has several soluble receptor isoforms resulting from alternative splicing of the full length mRNA or proteolysis of the cell-surface receptor, call as soluble Receptor for Advanced Glycation End Products (sRAGE) [3, 4]. An increased circulating total pool of sRAGE reflects enhanced tissue expression of RAGE in type 2-diabetic and non-diabetic subjects [5]. In healthy human volunteers, LPS administration leads to increased plasma sRAGE levels [6]. The exact role of sRAGE in plasma is unknown, but it may differ between different variants [7].

Osteoblasts are important cells that are responsible for bone formation. Any reduction in the number or function of these cells to synthesize new bone matrix may result in osteoporosis [8, 9]. The effect of methylglyoxal on mature osteblast is mediated by apoptosis through biochemical pathways, including c-Jun N-terminal kinase (JNK) activity, change of mitochondria membrane, release of cytochrome $\mathrm{C}$, increase $\mathrm{Bax} / \mathrm{Bcl}-2$ ratio, and the activation of caspase 3 and 9. In vivo study showed that administration of methylglyoxal at concentration 100-200 microgram via drinking water, increase losses of bone mineral density of rats [10]. At the cellular level, reactive oxygen species (ROS) may act as second messengers in various signal transduction and elicits a wide spectrum of responses ranging from proliferation to growth or differentiation arrest to senescence and cell death by activating numerous major signaling pathways. The magnitude and duration of the stress as well as the cell type involved are important factors in determining which pathways are activated, and the particular outcome reflects the balance between these pathways [11]. Increased levels of reactive oxygen species (ROS) influence numerous cellular processes and have been linked to development of osteoporosis, but the molecular details of the pathogenetic effects of oxidative stress on tissue homeostasis, such as production of SRAGE are not well understood. To understanding the involvement of 


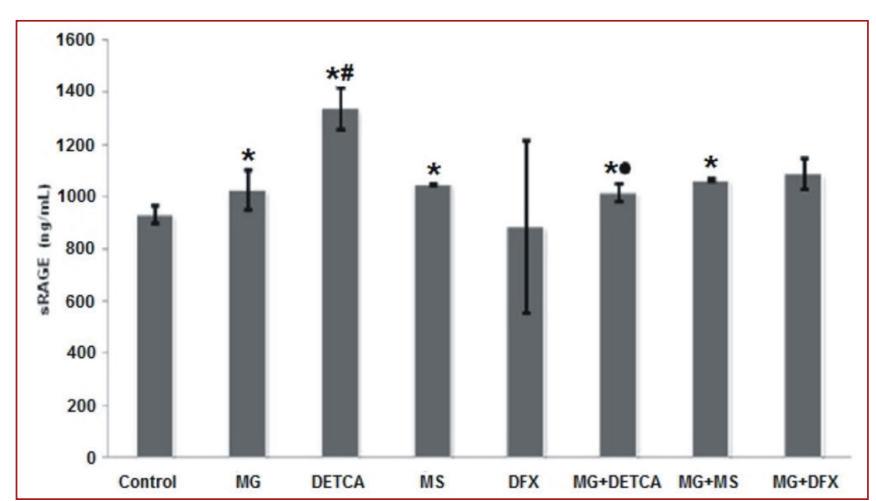

Figure 1. The effects of blockade SOD, GPX or iron chelating on sRAGE levels in MC3T3E1 preosteoblast cells. SOD: superoxide dismutase; GPX: glutathione peroxidase; DETCA: diethylthiocarbamoic acid; MS: mercapto succinate; DFX: defferoxamine; MG: methylgyoxal; sRAGE: Soluble Receptor for Advanced Glycation End Products; ng/ml: nanogram/mililiter; *: $p<0.05$ in comparison with control group; \#: $p<0.05$ in comparison with MG group; $\bullet$ $\mathrm{p}<0.05$ in comparison with DETCA group.

methylgyoxal in osteoporosis, this in vitro study was aimed to evaluate the effect of changes of intracellularly redox status on SRAGE levels of MC3T3E1 preosteoblast cell line.

\section{Material And Methods}

\section{Cell line}

MC3T3E1 preosteoblast cell line subclone 4 was obtained from American Type Culture Cell Collection (ATCC). MC3T3E1 preosteoblast cell line was exposed to MG at concentration $5 \mu \mathrm{M}$ for 6 hours of incubation time [12]. Oxidant pathway obtained using blockade of superoxide dismutase blockade (Diethylthiocarbamoic acid/DETCA), blockade of gluthatione peroxidase (mercaptosuccinate/ MS), and iron chelating (defferoxamine/DFX). Control group is MC3T3E1 preosteoblast cell line 4 without MG-exposed and blocking/chelating exposed. We divided into four groups, including control group, DETCA/MS/DFX-exposed group, MG-exposed group, and MG+DETCA/MS/DFX-exposed group.

\section{Cell culture}

We maintained cloned MC3T3-E1 osteoblast-like cells in normal media (NM) consisting of alpha MEM medium with $10 \%$ fetal calf serum (FCS), $1 \%$ antibiotic solution and $1 \%$ glutamine solution and subcultured the cells every 3 to 4 days. The cells were subcultured by incubating with trypsin for five minutes and resuspending at a concentration of $3 \times$ 105 cells $/ \mathrm{ml}$. For experiments, we grew the cells in the NM above, using multi-well plates. We used at least triplicate independent biological samples in multiple experiments for data collection. DETCA/MS/DFX were added simultaneous with MG exposure.

\section{Analysis of SRAGE}

The analysis of sRAGE was measured in culture medium using commercial available kit rat/mouse soluble receptor for advanced glycosylation end products (sRAGE) ELISA kit from Adipobioscience (Santa Clara, USA) with catalogue number 5K00112-03.

\section{Results}

Table 1 showed the effect of DETCA and MS, an inhibitor of superoxide dismutase and glutathione peroxidase on
SRAGE expression in MC3T3E1 preosteoblast cell line. Besides, the effects of DFX (iron chelator) also evaluated. Levels of SRAGE was significantly increased by MG or DETCA compared with control group $(P<0.05)$. The levels of sRAGE in MG+DETCA-exposed group was not significantly different than that of MG-exposed group ( $P>0.05$ ), but significantly decrease compared with DETCA-exposed group $(P<0.05)$. Levels of sRAGE was significantly increased in MS-exposed group or MG+MS-exposed group than that in control group, respectively $(P<0.05)$. Levels of sRAGE from $M G+M S$ exposed group was not significantly different compared to MG-exposed group or MS-exposed group ( $P$ $>0.05)$. The level of sRAGE were not significantly different between group of iron chelating $(P>0.05)$.

\section{Discussion}

Plasma methylglyoxal may be reaching $\sim 0.4 \mathrm{mmol} / \mathrm{l}$ in poorly controlled type 2 diabetic patients [13]. The methylglyoxal concentrations utilized in our experiments have previously been used by previous investigator [14].

Soluble RAGE (sRAGE) is pleotropic molecule as antagonist of RAGE. SRAGE also act as scavenger receptor for AGES [15, 16]. SRAGE was formed by a disintegrin and metalloproteinase-10 (ADAM10) domain via proteolitic pathway of RAGE [17]. SRAGE only have extracellular domain without transmembrane and cytoplasmic domain. Previous studies showed that SRAGE have beneficial effect. Infusion administration of SRAGE in diabetes mellitus rats showed atherosclerosis reparation [18].

Most tissues express low levels of mRAGE normally and then up-regulate expression of this protein with injury and disease [19]. This is first time study to measure the level SRAGE in preosteoblast MC3T3E1 cell line. We found the basal expression of SRAGE in preosteoblast MC3T3E1 cell line. This basal level act as decoy receptors to inhibit negative effect from AGEs. Studies with RAGE knockout mice that do not express sRAGE or full-length RAGE suggest that sRAGE acts via inhibition of RAGE-dependent phenomena [20]. Besides, methylgyoxal exposure significantly increases SRAGE levels. This finding indicates that MG exposure increase proteolitic activity of RAGE as homeostatic mechanisms. This finding provide novel proof that preosteobalst cell have response effect into pre-AGEs compound not only AGEs. sRAGE up-regulation to protect against $A G E$-accumulation and induction of tissue damage have been postulated [6]. SRAGE acts as an antagonist inhibiting the RAGE dependent signalling pathways, or as a binder of various RAGE ligands such as AGEs. SRAGE or possibly a nonpeptide RAGE antagonist may thus become a future therapeutic target [21]. Treatment with sRAGE significantly attenuated the increase in neutrophil infiltration, lung permeability, production of inflammatory cytokines, nuclear factor (NF)-KB activation, and apoptotic cells in the lungs [22].

We also found that blockade of superoxide dismutase or glutathione peroxidase significantly increase sRAGE levels. This results indicated that the accumulation superoxide radical from superoxide dismutase blocking also increase 
proteolitic activity of RAGE. Besides, the blocking of glutathione peroxidase produce sRAGE in similar level of with MG exposure. This finding also revealed that the changes intracellulary redox status will increase sRAGE levels.

The blockade of superoxide dismutase and glutathione peroxidase concomitant with methylgyoxal exposure also increases sRAGE level compared with control, but have similar levels with methylgyoxal exposure only. This finding suggested that there is antagonist mechanism that inhibit proteolitic activity of RAGE maybe due to blocker administration. The levels of SRAGE expression are significantly higher in DETCA-exposed group compared to control, MG-exposed or MG+DETCA-exposed group. This results revealed that superoxide radical has important role in proteolitic activities of RAGE and the presence of MG inhibit this mechanisms. Previous studies showed that induction of superoxide radicals by shock wave potentially may provoke intracellular signaling transduction, which in turn may activate angiogenic activity of bone cells. Besides, the general concept that a family of $\mathrm{NAD}(\mathrm{P}) \mathrm{H}$-dependent oxidoreductases may be present in nonphagocytic cells that function as generators of redox signal in response to various growth factor and physical stimulation [23].

In conclusion, the change of redox status by antioxidant blocker or MG exposure would increases SRAGE levels in preosteoblast MC3T3E1 cell line. The modulation of redox state by antioxidant blocker does not affect sRAGE level in the presence of MG. Iron chelating does not change the sRAGE expression.

\section{Acknowledgment}

The author thank to all technicians, (especially Mrs. Helly N Karima, S.Pt., MP) in Central Laboratory of Life Science, University of Brawijaya, Malang for helping this experiment.

\section{Conflict Of Interest}

No declared

\section{References}

1. Schalkwijk CG, Bezu J, van der Schors RC, Uchida K, Stehouwer CDA, van Hinsbergh VWM. Heat-shock protein 27 is major methylgyoxal-modified protein in endothelial cells. FEBS Lett 2011; 580:1565-70.

2. Oliveira LMA, Lages A, Gomes RA, Neves $H$, Familia C, Coelho AV, Quintas A. Insulin glycation by methylglyoxal results in native-like aggregation and inhibition of fibril formation. BMC Biochem 2011; $12: 41$.

3. Yamagishi S, Imaizumi T: Serum levels of soluble form of receptor for advanced glycation end products (sRAGE) may reflect tissue RAGE expression in diabetes. Arterioscler Thromb Vasc Biol 2007; 27:33-4.

4. Nakamura K, Yamagishi S, Nakamura Y, Takenaka K, Matsui T, Jinnouchi Y, Imaizumi T. Telmisartan inhibits expression of a receptor for advanced glycation end products (RAGE) in angiotensin-II-exposed endothelial cells and decreases serum levels of soluble RAGE in patients with essential hypertension. Microvasc Res 2005, 70:137-41.
5. Arabi YM, Dehbi M, Rishu AH, Baturcam E, Kahoul SH, Brits RJ, Naidu B, Bouchama A. sRAGE in diabetic and non-diabetic critically ill patients: effects of intensive insulin therapy. Critical Care 2011; 15:203.

6. Soop A, Sunden-Cullberg J, Albert J, Hallstrom L, Treutiger CJ, Sollevi A. Adenosine infusion attenuates soluble RAGE in endotoxin-induced inflammation in human volunteers. Acta Physiol 2009; 197:47-53.

7. Yonekura $H$, Yamamoto $Y$, Sakurai S, Petrova RG, Abedin MJ, Li H, Yasui K, Takeuchi M, Makita Z, Takasawa S, Okamoto $\mathrm{H}$, Watanabe T, Yamamoto $H$. Novel splice variants of the receptor for advanced glycation end-products expressed in human vascular endothelial cells and pericytes, and their putative roles in diabetes-induced vascular injury. Biochem J 2003; 370:1097-109.

8. Nishida S, Endo N, Yamagiwa H, Tanizawa T, Takahashi HE. Number of osteoprogenitor cells in human bone marrow markedly decreases after skeletal maturation. J Bone Mineral Metab 1999; 17(3):171-7.

9. Arjmandi BH, Juma S, Beharka A, Bapna MS, Akhter $\mathrm{M}$, Meydani SN. Vitamin $\mathrm{E}$ improves bone quality in the aged but not in young adult male mice. J Nutr Biochem 2002; 13(9):543-9.

10. Chan $\mathrm{W}, \mathrm{Wu} \mathrm{H}$. Protective effects of curcumin on methylglyoxal-induced oxidative DNA damage and cell injury in human mononuclear cells. Acta Pharmacol Sinica 2006; 27(9):1192-8.

11. Bai X, Lu D, Liu A, Zhang Z, Li X, Zou Z, Zeng W, Cheng $B$, Luo $S$. Reactive oxygen species stimulates receptor activator of NF-kB ligand expression in osteoblast. J Biol Chem 2005; 280(17):17487-506.

12. Akbar IZ, Permatasari N, Soeatmadji DW, Hidayat $M$, Kalim H. Reactive oxygen species and cell morphology of MC3T3E1 pre-osteoblast cell line exposed to methylgyoxal by laser scanning confocal microscopy. Oxidant Antioxid Med Sci 2013; 2(1):65-8.

13. Lapolla A, Flamini R, Dalla Vedova A, Senesi A, Reitano R, Fedele D, Basso E, Seraglia R, Traldi P. Glyoxal and methylglyoxal levels in diabetic patients: quantitative determination by a new GC/MS method. Clin Chem Lab Med 2003; 41:1166-73.

14. Riboulet-Chavey A, Pierron A, Durand I, Murdaca J, Giudicelli J, Obberghen EV. Methylglyoxal impairs the insulin signaling pathways independently of the formation of intracellular reactive oxygen species. Diabetes 2006; 55:1289-99.

15. Basta G, SchmidtAM, Caterina RD. Advanced glycation end products and vascular inflammation implicatiosn for accelerated atherosclerosis in diabetes. Cardiovasc Res 2004; 63:582-92.

16. Yan SF, Ramasamy $R$, Naka $Y$, Schmidt AM. Glycation, inflammation, and RAGE: a scaffolde for the macrovascular complications of diabetes and beyond. Circ Res 2003; 93:1159-69. 
17. Bucciarelli LG, Wendt T, Qu W. RAGE blockade stabilizes established atherosclerosis in diabetic apolipoprotein E-null mice. Circulation 2002; 106:2827-35.

18. Oliver EA, Buhimschi CS, Dulay AT, Baumbusch MA, Abdel-Razeq SS, Lee SY, Zhao G, Jing S, Pettker CM, Buhimschi IA. Activation of the receptor of advanced glycation end products system in women with severe preeclampsia. J Clin Endocrinol Metab 2011; 96(3):689-98.

19. Lizotte PP, Hanford LE, Enghild JJ, Nozik-Grayck E, Giles BL, Oury TD. Developmental expression of the receptor for advanced glycation end-products and its response to hyperoxia in the neonatal rat lung. BMC Dev Biol 2007; 7:15.

20. Bierhaus A, Humpert PM, Morcos M, Wendt T, Chavakis T, Arnold B, Stern DM, Nawroth PP (2005) Understanding RAGE, the receptor for advanced glycation end products. J Mol Med 83:876-86
21. Goh SY, Cooper ME. Clinical review: the role of advanced glycation end products in progression and complications of diabetes. J Clin Endocrinol Metab 2008; 93:1143-52.

22. Zhang H, Tasaka S, Shiraishi $Y$, Fukunaga $K$, Yamada W, Seki H, Ogawa Y, Miyamoto K, Nakano Y, Hasegawa $\mathrm{N}$, Miyasho T, Maruyama I, Ishizaka A. Role of soluble receptor for advanced glycation end products on endotoxin-induced lung injury. Am J Respir Crit Care Med 2008; 178:356-62.

23. Wang FS, Wang CJ, Chen YJ, Chang PR, Huang YT, Sun YC, Huang HC, Yang YJ, Yang KD. Ras induction of superoxide activates ERK-dependent angiogenic transcription factor HIF-1 and VEGF-A expression in shock wave-stimulated osteoblast. J Biol Chem 2004; 279(11):10331-7. 